\title{
4 \\ Bringing Industrial and Health Policies Closer: Reviving Pharmaceutical Production in Ethiopia
}

Tsige Gebre-Mariam, Kedir Tahir and Solomon Gebre-Amanuel

\section{Introduction}

Manufacturing of medicines in Ethiopia started in 1964 with the establishment of one joint venture manufacturing company. This company remained the sole producer of medicines throughout the military regime (1974-91). Following the regime change in 1991, several manufacturing plants were established during the period referred to as the 'boom and crash' period, since, for reasons described below, some of the new companies were not successful. To respond to the crisis, the government took a mix of initiatives, simultaneously fulfilling its responsibility for health care improvement and industrial promotion. As a result of policy adjustments and attractive incentives, the environment for investment in pharmaceuticals became conducive, prompting private initiative to engage in industrial investment. Joint ventures that were realized have not only contributed to the pharmaceutical industry; they also effectively transferred skill and technology.

This chapter argues for the importance of integrating the health and industrial policies to foster local pharmaceutical production. We argue that local production of pharmaceuticals is justified from both industrial and health polices standpoints. From an industrial policy standpoint, local pharmaceutical manufacture is usually justified by its benefits for the local economy, such as savings on foreign exchange through 
import substitution, employment creation and the development of exports. From a health policy perspective, the rationale for local pharmaceutical manufacture is largely founded on increasing the access to essential medicines. Ethiopia is a country with high disease burden; it therefore considers development of the pharmaceutical industry a strategic endeavour.

The chapter is organized to demonstrate the close interconnections between industrial and health improvement in recent Ethiopian experience. After an overview of the stages of pharmaceutical industrial development in Ethiopia over the last 50 years, the chapter turns to an examination of the context and framework of Ethiopian health policies and the supply of medicines, describing the importance of medicines demand for the industry and industrial supply for health sector development. We describe how the health sector development programme is linked to the provision of essential medicines in the primary health care (PHC) system of the country, and the government's social responsibility in providing medicines to the population.

A key objective of the chapter is to argue, on Ethiopian evidence, that joint ventures in the pharmaceutical industry can be designed as strategic partnerships. It narrates some success stories in terms of technology transfer and upgrading manufacturing plants, and localization of knowledge within Ethiopia, and their roots in a conducive policy environment for private sector investment. A final section examines these developmental aspects of Ethiopian industrial policies. In conclusion we acknowledge the headway Ethiopia has made in manufacturing medicines and identify some issues to be addressed.

In the preparation of this chapter, policy documents, proclamations, regulations, guidelines and literature were reviewed. Key informant interviews were conducted and plant visits undertaken by the authors.

\section{Pharmaceutical industrial development in Ethiopia}

\section{Phases of industrial development}

The history of pharmaceutical manufacturing in Ethiopia is only half a century old and it may be classified into three periods: the establishment of the Ethiopian Pharmaceutical Manufacturing company (EPHARM), the subsequent boom and crash and the later 'reform and revival' period.

The first pharmaceutical manufacturing plant in Ethiopia, EPHARM was founded in 1964 as a joint venture by the Ethiopian government and the British company, Smith \& Nephew. In 1971, Smith \& Nephew 
was superseded by Teva Jerusalem of Israel. Following the overthrow of the monarchial government by the military in December 1975, the company was nationalized. Due to the socialistic policy of the military regime, private industrial investment generally stagnated and EPHARM remained the sole producer of medicines in the country until 1993. In February 1994, EPHARM was re-established as a public share holding company and recently it was sold to a local investor.

The period 1995 to 2004 experienced the boom and crash. Ten new pharmaceutical plants were established: Asmi Industry PLC, East African Pharmaceuticals (EAP), Addis Pharmaceuticals Factory (APF), ETAB PLC, Pharmacure PLC, BioSol PLC, Life-Line PLC, Fews PLC, Sino-Ethiop Associate (Africa) PLC (SEAA) and Bethelehem PLC. However, the new factories faced daunting challenges, as there were neither policies nor regulatory mechanisms to control dumping of cheaper and substandard products. The prices of local products were not competitive. In addition, most of the new factories were poorly organized and managed. Consequently, four companies were foreclosed for failure to service their loan obligations.

According to the secretary of the Ethiopian Pharmaceuticals and Medical Supplies Manufacturing Association (PMSMA), the production capacities of the majority of the industries at the time was below $50 \%$ of their installed capacity. There was a high tariff on raw materials and a chronic shortage of experienced human resources, associated with high turnover of technical staff, shortage of technical manpower, and an absence of any training centre on good manufacturing practices (GMP) and pharmaceutical management. In addition there were no GMP-certified inspectors at the regulatory authority. It was hard to get working capital from banks, there were management problems in the industries, an absence of qualified equipment calibration and maintenance centres, and university-industry linkages were weak.

Established in 1996, East African Pharmaceuticals (EAP) was one of the companies that survived the 'crash' period. EAP was an initiative of British and Sudanese nationals. It had difficulties at the outset when the cost of the investment was driven up due to the decision of Drug Administration and Control Authority (DACA) that EAP should reconstruct its plant to comply with GMP, shortly after it started operation. In 2009 , the factory was operating at $30 \%$ of its capacity. EAP produces human and veterinary medicines mainly for the local market, although a small portion is exported to Sudan and Somali. Being the only local manufacturing company producing veterinary medicines, EAP enjoys market monopoly. Hence, it is currently considering increasing its 
production to meet the market demand. At the time of writing EAP has just achieved a GMP Certificate from the Pharmaceutical Inspection Convention and Pharmaceutical Inspection Co-operation Scheme (PIC/S).

Established in 1997, Addis Pharmaceuticals Factory (APF) Sh. Co. is the largest pharmaceutical manufacturing plant in Ethiopia. It is located in Adigrat, Tigray Regional State, northern Ethiopia. Though the plant was constructed and equipped with high-tech production facilities, at the start it faced financial and management crisis. In 2009, it acquired a second factory located at Akaki at the outskirts of Addis Ababa, which is dedicated to the manufacturing of large-volume parenterals. APF manufactures about 90 products. It has nine production lines with a capacity to produce 1.2 billion tablets, 19 billion ampoules, 10 million vials, 500,000 capsules, 4 million ointment tubes and 9.6 million bottles of syrup. It has fully equipped laboratories. APF is owned and managed by the Endowment Fund for the Rehabilitation of Tigray (EFFORT). ${ }^{1}$

Sino-Ethiop Associate (Africa) PLC (SEAA) was established in March 2001 as a joint venture between an Ethiopian company, Zaf Pharmaceuticals PLC, and two Chinese companies (China Associate Group and Dandong JINWAN Group). SEAA produces empty hard gelatin capsules and sells them to pharmaceutical factories in Africa and the Middle East. Recently, SEAA completed its expansion project and doubled its production capacity, to 2.4 billion capsules annually. SEAA has recently acquired Certificate of PIC/S conformity. It will be shown later that companies established through joint venture have been generally successful.

The 'reform and revival' period began in 2005. The Ethiopian Pharmaceutical and Medical Supplies Manufacturers Association (EPMSMA) and other key stakeholders appealed to the government for appropriate measures to be taken in support of local manufacturing. To address the crisis the local manufacturers were facing, the government created benefit packages and undertook policy reforms. This improved the business environment, resulting in some new joint ventures.

In 2007, Cadila Pharmaceuticals Ethiopia PLC (CPEL) was established by Cadila Pharmaceuticals Ltd (India) and Almeta Impex PLC (Ethiopia), owning $57 \%$ and $43 \%$ of the company, respectively. The market size, including easy access from Ethiopia to other East African countries, motivated the investment. All machines and raw materials were imported from India. CEPL has the capacity to manufacture 390 million tablets, 165 million capsules and 1.44 million litres of liquid per annum. In 2011, CEPL acquired a GMP certificate. ${ }^{2}$ 
Established in 1998, Pharmacure PLC, a Swedish turnkey plant, is an Ethiopian-Saudi investment. It produces large-volume parenterals. Rx Africa (Ethiopia) PLC, an Ethiopian-US joint venture was commissioned in 2007 through the acquisition of a local company called Sunshine Pharmaceuticals. Rx Africa launched 36 products in 2009. Another local manufacturer, Fews PLC, produces syrups.

In 2013, Julphar (Gulf Pharmaceutical Industries) commissioned its pharmaceutical manufacturing facility ${ }^{3}$ in Addis Ababa. The facility has the capacity to produce 150 million bottles of suspension and syrup, 500 million tablets and 170 million capsules annually.

One unique local manufacturer is the National Veterinary Institute located in Bishoftu, $40 \mathrm{~km}$ south of Addis Ababa. With its well-equipped diagnostic and research laboratories and production plants, the NVI is currently producing $19 \mathrm{R} \& D$-based veterinary bacterial and viral vaccines for both domestic and international markets to more than 25 countries in Africa and the Middle East.

\section{The Ethiopian industry today}

Today, the Ethiopian pharmaceutical industry consists of 15 pharmaceutical manufacturers, of which nine produce medicines, one manufactures empty gelatin capsules, and the rest are engaged in producing medical supplies such as syringes, absorbent cottons, gauzes, bandages and sanitary products. Though significant expansion of the industry is taking place, as such the base is not yet well developed, and the companies have relatively low production capacities.

The therapeutic categories of local production include antibiotics, gastrointestinal drugs, central nervous system drugs, cardiovascular drugs, anti-diabetic agents, antihistamines, anthelmintics, analgesics and antipyretics, antiprotozoals, respiratory drugs, dermatological preparations, minerals and vitamins, large-volume parenterals as well as veterinary vaccines. None of the manufacturers produces medicines against tuberculosis, HIV/AIDS and malaria. Since the local manufacturers were not GMP-compliant, they could not make use of the donor funding made available for the procurement of medicines for these diseases. Hence these medicines are being imported from abroad, mainly from Indian manufacturers.

The Ethiopian pharmaceutical industries are small- to medium sized industries. Most use labour-intensive, step-by-step manual manufacturing, with semi-automated production lines. Manufacturers mainly focus on tablets, capsules, powder and liquid preparations. A few produce parenteral preparations, creams and ointments. Production is limited 
to secondary manufacturing that involves combining and processing pharmaceutical active ingredients (APIs) and excipients into dosage forms. There is no active pharmaceutical ingredient (API) plant in the country. Almost all input materials (APIs and excipients), including primary packaging materials, are imported, mainly from India and China. According to an interview with the procurement department manager of EPHARM, input materials are purchased in small quantities, at times too small to attract suppliers, and as a result manufactures have no power to negotiate better prices. This situation tends to increase the cost of input materials. Hence, most of the finished products are not competitive as compared to products imported from China and India. Just a few inputs such as sugar (for syrup production), empty hard gelatin capsules and secondary packing materials are locally produced. There are new packaging manufacturers who have begun producing PVC and empty bottles for pharmaceutical use replacing some of the imports (Sutton and Kellow, 2010). Cardboard boxes for bulk packaging are manufactured locally.

Although most of the manufacturers operate below their respective capacities, the capacity utilization of the manufacturers has shown improvement during the 2005-14 period, increasing from a mere $29.3 \%$ in 2008 to $79.0 \%$ in 2013 . This is indicative of the growing market for locally produced pharmaceuticals - an opportunity lying ahead for the sector (CSA, 2014).

As regards quality issues, there are three manufacturers that comply with basic GMP standards, one of whom is to acquire PIC/S Certification soon, while two others are expected to acquire the same in the near future. One of the main issues that must be addressed by local manufacturers is the need to access updated technology. In terms of personnel, however, Ethiopia seems to have sufficient trained pharmacists, though there is a dire need for those with industrial and managerial skills.

\section{Developing and supplying the health sector}

This section analyses the interaction of health care development and industrial market development, aiming to show how health and medicines policies influenced the development of the local pharmaceutical industry.

The National Health Policy (NHP) launched in 1993 includes as core elements the development of preventive, promotive and curative health care; assurance of health care accessibility for all segments of the population; and the promotion of private sector and NGO participation 
in the health sector (TGE, 1993a). In order to achieve these goals, a 20-year Health Sector Development Programme (HSDP) consisting of a series of five-year rolling programmes was established in 1997/98. The HSDP has been aligned with the wider frameworks of the Plan for Accelerated Development to End Poverty (PASDEP), and a Growth and Transformation Plan (GTP) has been formulated and implemented.

HSDP implementation takes a sector-wide approach encompassing the following components: service delivery and quality of care; health facility rehabilitation and expansion; human resource development; pharmaceutical services; information, education and communication; health sector management and management of information systems; monitoring and evaluation and health care financing.

Over the last two decades the government has been engaged in health facility construction, expansion, rehabilitation, furnishing and equipping. From 2003/04 to 2011, the number of health posts increased from 4,696 to 17,972 and the number of public health centres from 519 to 3,871 , while the number of hospitals (public and private) rose from 126 to 194 (FMOH, 2011). Health service coverage increased from $45 \%$ in 2001 to $95 \%$ by 2011 . The rise in health service coverage necessitated an increased demand for pharmaceuticals. Hence, the number of pharmaceutical manufacturers, importer/distributors and retail outlets increased significantly during the same period to serve an expanding market.

Targets set by HSDP IV with respect to pharmaceutical supply and services include increasing the availability of quality pharmaceuticals at an affordable price and in a sustainable manner, and achieving improved rational drug use. In the design of HSDP III and IV, the SWOT analysis made indicated increasing domestic manufacturing capacity of drugs as an opportunity to be explored (FMOH, 2011/12). Recognizing the importance of the supply of pharmaceuticals in the overall health policy, the government decided to increase the availability of essential pharmaceuticals from $75 \%$ to $100 \%$ and improve the efficiency of regulatory activity (MOFED, 2006). Moreover, the Growth and Transformation Plan (GTP) anticipated increasing the domestic market share of the local pharmaceutical industry from the baseline year 2009/10 share of $15 \%$ to the target 50\% (MOFED, 2012).

The market for pharmaceuticals in Ethiopia is met through import (purchase and donation) and local production. Local manufacturing still represents less than $15 \%$ of the total market for pharmaceutical products. Governmental organizations, private importers, non-government organizations (NGOs) and international agencies such as the UNICEF 
and WHO used to participate in the import and distribution of pharmaceuticals. In order to streamline the supply and distribution of essential medicines to the public health care facilities, the former PHARMID was transformed into the Pharmaceutical Fund and Supply Agency (PFSA), as established by Proclamation in 2007 (FDRE, 2007).

Today, local and international procurement for the public health facilities is mainly provided by the PFSA which operates with a revolving fund. PFSA procurement is done through international and local tenders as well as through direct purchasing. The PFSA also receives some pharmaceuticals through donation from sponsors of vertical programmes such as those for ARVs, TB and malaria medication and reproductive health commodities. From its central hub in Addis Ababa and the regional hubs, PFSA distributes medicines and medical supplies directly to health care facilities. Private companies import directly from their respective suppliers and distribute to wholesalers, and these in turn sell to retailers.

The PFSA has designed and implemented different strategies to support local manufacturers of pharmaceuticals and medical supplies. These include the provision of $30 \%$ advance payment for the purchase of products won through national bidding and $25 \%$ price preference when local manufacturers participate in international bids. Although not yet implemented, a tripartite agreement (PFSA as a collateral, pharmaceutical companies and the Development Bank) has been signed, providing local manufacturers with a loan for $70 \%$ of a bid that has been won. Furthermore, to increase local production of pharmaceuticals and medical supplies and create market linkages with consumers, the type and amount of products given priority by the health services have been identified. Based on this, a list of 124 pharmaceuticals and medical supplies produced in the country has been prepared to serve as a guide for the procurement process.

With an estimated population of 95 million in 2014, Ethiopia has the potential to become a significant market for pharmaceutical products in Sub-Saharan Africa. Although the Ethiopian pharmaceutical market grew on average by $20 \%$ per annum from 2007 to 2011 , it is still rather limited, estimated at around US\$500 million, due mainly to low per capita income. Currently, there is slightly higher total health expenditure as a share of GDP, at $4.9 \%$ in Ethiopia, as compared to other countries in Africa (excluding South Africa), but the per capita health expenditure remains among the lowest in the region (Wamai, 2009). 


\section{Joint ventures and strategic partnerships: fostering technology transfer}

The revival of the pharmaceutical industry of Ethiopia after the boom and crash is largely attributed to policy reforms, investment and manufacturing incentive packages. One important phenomenon that stands out is joint ventures. Through the initiative of joint ventures, a foreclosed factory revived, an old factory was upgraded, new factories were established, and enhanced technology transfer included localization of technical knowledge within Ethiopia.

One of the shortcomings of the local manufacturers is that they are organized at the secondary level and hence dependent on foreign companies for raw materials and technology sources. In order to overcome this problem, some local manufacturers established joint ventures as a strategic partnership with foreign companies. These joint venture investors gain access to both local and regional markets, and Ethiopia's cheap labour force, as well as a number of investment incentives that the country offers in exchange for raw materials, know-how, technology transfer and pre-established market networks. This kind of strategic partnership can be considered as a key factor for long-term success. The joint ventures between the Ethiopian company, Zaf Pharmaceuticals PLC, and two Chinese companies, China Associate (group) Co., Ltd and Dandong Jinwan (Group) Co., Ltd (Sino-Ethiop Associate Africa PLC), and between Medtech (Ethiopia) PLC and Gulf Pharmaceuticals Julphar of UAE (Julphar Pharmaceuticals Manufacturing Ethiopia PLC) are based on this principle.

Sino-Ethiop Associate Africa PLC, the sole empty hard gelatin capsules (EHGCs) manufacturer in Africa, was established at the outskirts of Addis Ababa in March 2001 and became operational in June 2003. China Associate (Group) Co., Ltd. is a 35\% shareholder of Sino-Ethiop Associate Africa PLC. It is a diversified enterprise engaged in manufacturing of bulk pharmaceuticals and finished formulations and has a trading business. This company has more than ten years of business relationship with the pharmaceutical companies of some African countries, including Ethiopia. Dandong Jinwan (Group) Co., Ltd. is the other partner holding $35 \%$ of the shares. It is a diversified enterprise engaged in the production of EHGCs itself and manufacturing of equipment for capsules production. Zaf Pharmaceuticals PLC, engaged in importing of pharmaceuticals, is the Ethiopian counterpart in the joint venture, having $30 \%$ of the shares. 
The company currently has five automatic capsule production lines to produce EHGCs, with a total capacity of 2.4 billion EHGCs of size 0 , size 1 and size 2 per year. The continuous batch system is applied in the production process; as a result, production is not interrupted except during regular preventive maintenance schedule and size part changes. Its capacity utilization is normally more than $95 \%$, operating in three shifts. On average, there are more than 300 production days per year. The company covers $100 \%$ of the local EHGCs demand and exports to Sudan, Kenya, Uganda, South Africa, Ghana, Zimbabwe, Democratic Republic of Congo, Yemen and Saudi Arabia, among others.

The company has recently undergone a major expansion that transformed the overall capacity of the company, doubling the annual output. It has also done the civil engineering required to accommodate three more production lines. The director of the company revealed that the expansion has transformed the company in terms of both quality and productivity, including:

- state-of-the-art manufacturing equipment which is automatic and fully synchronized;

- Programmable Logic Controller (PLC) systems: advanced from pushbutton to touch-screen, enabling easy process monitoring and record keeping;

- heating, ventilation and air conditioning (HVAC) system: programmed based on a one-year study made on the climatic condition of the location in order to improve its overall efficiency;

- water treatment system: use the double-reverse osmosis system along with electro-deionization system that reduced the use of different chemicals and improved the quality of the water; and

- energy utilization: integrated a solar energy source with the existing grid supply.

After the expansion, the manufacturing lines were moved to the new plant, leaving the old facility empty. Although the company is working three shifts at full capacity, it is still unable to meet market demand for EHGCs. It is therefore planning to increase its capacity from five to eight lines at the new plant. Further, the company plans to convert the old facility into a formulation plant for contract manufacturing. The other plan of the company, which is also of interest to the government, is to look into the possibilities of developing gelatin raw materials from cattle bone, which is abundant in the country. 
Skills and technology transfer has been extensive. Over a period of ten years, the Chinese technical and managerial staff have been completely replaced by Ethiopian staff (today there is just one Chinese engineer). The technology has been totally transferred (by Dandong Jinwan), signifying the critical role that joint ventures can play in the development of the pharmaceutical industry. According to the general manager of the company, such a smooth transfer was possible due to several complementary reasons, including the trust developed among the partners, the government policy to limit the number of foreign employees in a company, training of personnel locally and abroad, and government insistence that the transfer of skills and technology by partners should take place.

Julphar Pharmaceuticals Manufacturing Ethiopia PLC is another company established as a joint venture. Its vision is to become one of the leading pharmaceutical companies in Africa by the year 2020 with a number of product portfolios. The joint venture is formed between an Ethiopian company, Medtech Pharmaceuticals PLC, that holds $45 \%$ of the shares, and a United Arab Emirates (UAE) company, Gulf Pharmaceuticals (Julphar), that holds 55\% of the shares. The UAE partner is producer of various pharmaceutical products in the Middle East and in its other subsidiaries in Algeria. Julphar maintains a network of 11 manufacturing plants based in the UAE, with developments under way to open additional facilities in strategic countries such as Saudi Arabia, Ethiopia and Algeria. It supplies its generic pharmaceutical products to the global pharmaceuticals markets. The Ethiopian partner has been exclusively importing and distributing Julphar products and continued to do so for products being produced locally by Julphar Ethiopia as well. ${ }^{4}$

This joint venture transformed a previously bankrupted manufacturing facility, Bethelehem Pharmaceuticals, into a viable, state-of-the-art facility at a cost of about US\$9.17 million. Currently, it is running at full capacity and producing and supplying the Ethiopian market with 25 different products ( 25 million bottles of syrup/suspension, 500 million tablets and 170 million capsules per year). In order to reach the international market, the company has already fulfilled GMP requirements and is expected to be fully certified with PIC/S.

The company has upgraded the facility with new utilities and machineries as per GMP requirements. It has put in place new HVAC system, state-of-the-art and fully automated reverse-osmosis water treatment system, and boilers for generation of pharmaceutical grade steam. Furthermore, to increase its product portfolio and production capacity, a new closed and fully automated oral liquid preparation and filling 
line, tablet compression and blistering machines, and ointment filling machines have been installed and made operational. To upgrade the quality control system, Julphar has introduced high-performance liquid and gas chromatography systems and computerized stability chambers. To enhance the quality assurance (QA) system, the company is transferring QA documentation systems such as product dossiers, procedures and validation protocols from the mother company in the Gulf.

According to the country director of Julphar UAE, the joint venture has been highly encouraged by Ethiopian market access and by the investment policy of the government. Accordingly, Julphar has also earmarked an additional investment worth US\$50 million to establish an insulin plant. To facilitate the expansion, the government of Ethiopia availed a plot of land for Julphar adjacent to its existing facility. This new investment is the first of its kind in Africa and it aims at making Ethiopia an insulin hub for the growing African insulin demand. ${ }^{5}$ This move is heralding the beginning of advanced manufacturing of pharmaceuticals of biological origin in Ethiopia.

To achieve its vision, Julphar Ethiopia PLC is interested in launching new investment in additional plant to produce products like B-lactams and small-volume injectable products. The director reiterated the challenges the company has been facing, including lack of trained and skilled engineers to install and maintain pharmaceutical machineries and facilities and the unavailability of spare parts and consumable materials in the local market. To deal with these challenges, the company has assigned engineers and technicians from the mother company. This arrangement has helped with technology and skill transfer for Ethiopian engineers. To overcome the shortage of trained and skilled manpower in the pharmaceutical industry, the company has made arrangements with local universities for the provision of on-the-job training within its facility and abroad in its mother company. Accordingly, a team of selected students from different universities were fully funded by the company for their stay in Julphar UAE to acquire knowledge and skill in the pharmaceuticals manufacturing sector. ${ }^{6}$ From the foregoing it is apparent that integrating health and industry polices is highly beneficial for industrial development, since it can attract and make good use of joint ventures.

\section{Socio-economic policies and the investment environment}

The last section referred to the Ethiopian government's incentives for local industry. This section explores those industrial and socio-economic 
policies in more depth. The Ethiopian government's industrial policies are developmental in nature, and pharmaceuticals are a key aspect of that broader approach. Consequently, the current investment climate of the country is considered propitious, since the country has several competitive advantages. Ethiopia has sizeable young and educated, trainable human resource and a large number of inexpensive labourers; rapidly developing green energy, as well as modest transportation infrastructure and trade logistics; and duty-free, quota-free access to the US and EU markets under the African Growth and Opportunities Act (Assefa et al., 2013).

Both the National Health Policy (NHP) (TGE, 1993a) and the National Drug Policy (NDP) (TGE, 1993b) emphasize the importance of local pharmaceutical production. The NHP states: 'Availability of drugs, supplies and equipment shall be assured by encouraging national production capability of drugs, vaccines, supplies and equipment by giving appropriate incentives to firms which are engaged in manufacture, research and development' (TGE, 1993a). One of the objectives of the NDP also specifies: 'To develop a domestic drug manufacturing capacity and gradual supply to the export market' (TGE, 1993b). Given the significant headway Ethiopia has made in availing access to PHC for its people, and given the country's ambitious local pharmaceutical manufacturing plans, the NDP is currently being revised to lead GTP II and GTP III.

The regulatory body previously known as DACA was restructured (with greater mandates including improved regulation, and setting standards in health care facilities as well manufacturing companies) and re-established as the Food, Medicine and Healthcare Administration Control Authority (FMHACA) by Proclamation, and has set standards for manufacturing facilities, among others (FDRE, 2009). Even though the primary responsibility of FMHACA is to regulate and control medicines, it has been building the capacity of the local manufacturers in GMP in collaboration with the WHO and the United States Agency for International Development (USAID) programme 'Promoting the Quality of Medicines' and United States Pharmacopeial Convention (PQM/USP).

The other sectoral polices that Ethiopia has put in place that in one way or another have contributed to the overall socio-economic developments (including the local pharmaceutical industry) are trade policies (focusing on business transactions such as the pharmaceutical supply chain), industrial policies (focusing on fostering manufacturing and technology transfer) and investment and labour policies. Since the implementation of the 1991 Trade Policy, Ethiopia has made significant 
progress in opening up its economy and notable improvements have been recorded in its international trade.

\section{Industry Policies}

Ethiopia's Industry Policy dates from August 2001 and is designed within the framework of a free market economy. The key principles of the strategy include recognition of the role the private sector as an engine of industrial development and facilitation by the government towards that end; an agricultural development-led industrialization strategy; and ultimately export-led industrialization. It focuses on labour-intensive industries and aims to coordinate foreign and domestic investment.

Local pharmaceutical production in developing countries has always been a debatable issue. On one hand, there are opinions that argue against local pharmaceutical production for lack of comparative advantage, including absence of GMP and inadequate drug regulatory systems. These critics are also concerned with the immediate and long-term threats posed by low-quality medicines manufactured by African countries. People on the other side of the debate consider essential medicines as strategic commodities and seek to foster self-reliance and hence local production (Bate, 2008). The Ethiopian industry policy fosters the latter approach.

The investment policy within Ethiopia's industrial policy framework encourages the private sector to invest in almost all areas of economy. The policy does not impose local content, technology transfer (although encouraged) or export performance requirements on foreign investments. Export-oriented sectors receive long-term credit with low interest, export incentives, customs duty privileges and provision of land at competitive rents. The Development Bank of Ethiopia offers up to $70 \%$ of the investment capital for new investments or expansion projects in the pharmaceutical sector, with a $7.5 \%$ interest rate and a long-term repayment horizon. Investors in the manufacturing sector will have customs duty privileges for capital goods and construction materials necessary for the investment, spare parts whose value is not greater than $15 \%$ of the total value of the capital goods and tax holiday privileges between two and seven years. There are no restrictions on repatriation of earnings, capital, fees or royalties (EIC, 2014).

Recognizing the role of the private sector in the economy, the government of Ethiopia revised its investment law at least three times between 1992 and 2012. The revisions rendered investment incentives more transparent, attractive and competitive. Major positive changes regarding 
foreign investments have also been introduced through Investment Proclamation No.769/2012 and Regulation No. 270/2012, which detail the tax incentives and duty-free privileges for investors.

In general, there are a number of reasons for potential investors to consider Ethiopia as a desirable location for pharmaceutical investment, including factors such as investor-friendly policies, conducive macroeconomic policies and stable foreign exchange rates, a sizeable local market, access to the markets of several African countries through COMESA, preferential trade treatment to the EU, ACP-EU, a favourable export market under the US Generalized System of Preference, abundant and inexpensive skilled and trainable workforce, strategic location with proximity to the lucrative markets of the Middle East, Europe and Asia and attractive incentive packages for investment.

Ethiopia is a member of the World Bank-affiliated Multilateral Investment Guarantee Agency, which gives foreign investors guarantees against non-commercial risks. Ethiopia is a signatory to several bilateral and multilateral investment promotion and protection treaties. Ethiopia has also signed the World Bank Treaty on "The Convention on Settlement of Investment Disputes between States and Nationals of other States'.

The country's current labour policy is based on Labour Proclamation No. 377/2003 which calls for workers and employers to comply with basic principles of rights and obligations, through co-operative efforts (FDRE, 2004) in conformity with international conventions and other legal commitments to which Ethiopia is a party. Abundance of inexpensive and disciplined labour together with the introduction of the revised labour proclamation is believed to contribute positively towards competition in the industry and other sectors.

\section{Science and technology policies}

One of the key indicators of the socio-economic development and technological progress of a country is the contribution of the industrial sector to the economy. The Ethiopian government has recognized that science and technology are the major driving forces behind industrialization. It is taking steps to foster the growth of science, technology and innovation (STI), including the promotion of indigenous knowledge to tackle the country's needs (see also Chapter 7).

The Ministry of Science and Technology (MoST) recently published a document called the 'Green Paper on Science, Technology and Innovation Policy of Ethiopia-Building Competitiveness through Innovation' (MoST, 2012). In this document the pharmaceutical industry has not only been 
listed as one of the high-level technology industries but also identified as an area in which efforts will be geared to building domestic technological capability. According to the paper, the pharmaceutical industry is among the National Priority Technology Capability Programmes of Ethiopia.

The national science and technology policy of the country dates from 1993. Although this policy served to provide general directions to guide scientific and technological activities, it was not followed by implementation strategies and programmes aimed at achieving the envisaged policy objectives. It was therefore revised in 2012. The revised policy directives and strategies indicate, among other things, that at least 1.5\% of the country's gross national product (GNP) will be allocated annually to support and sustain the different STI activities in all sectors. A centralized innovation fund for R\&D activities will be created through a contribution of $1 \%$ of the annual profit of all productive and service sectors, and banking and financial institutions will be encouraged through various legal and incentive mechanisms to improve their role of fostering technological innovation (MoST, 2013).

The policy landscape of Ethiopia entered a new phase when the Ethiopian government launched the GTP I (2010/11-2014/15). As the highest national policy framework, the GTP governs Ethiopia's developmental policies, budgets and government organizations, as well as actions of development partners and foreign investors. Among other things, the GTP is tuned to expand infrastructure significantly and increase the role of the manufacturing industry in employment and economic development. The GTP identifies the pharmaceutical industry as a priority sector. Moreover, government support for the priority sectors will focus on, among other things, expanding modern systems in the sector by using local and external technical support and ensuring foreign technical support and investment, focusing on management skills and transformation, technological transfer and capacity building. The market share of local pharmaceutical producers is targeted to reach $50 \%$ by 2015 (MoFED, 2010).

For this set of objectives, regulatory support is essential. As part of the GTP, the FMHACA has been implementing a five-year project which states: 'The main aim of the pharmaceutical industry is substituting essential medicines imported to the country and setting the ground for export of local products by building the capacity of existing pharmaceutical and medical device manufacturers and establishing new ones'. Notwithstanding the responsibilities vested in the authority by Proclamation 661/2009 to ensure the safety, efficacy and quality of 
products, the FMHACA together with stakeholders has been exerting efforts to build the technical capacity of local manufacturers.

The FMHACA's ambitious project envisioned 17 local GMP-certified pharmaceutical manufacturers by the end of 2015; at least five pharmaceutical manufacturers pre-qualified by WHO by 2015; seven newly established pharmaceutical manufacturers by the end of 2015; and two newly established pharmaceutical raw materials manufacturers and two newly established traditional medicines manufacturers (FMHCA, 2011). To build the capacities of the local pharmaceutical manufacturers, FMHACA also prepared the Medicine Manufacturing Establishment Directive, and it has made it mandatory for any person engaging in manufacturing medicines to obtain a Certificate of Competence from the Authority (FMHCA, 2013a).

FMHACA, working together with the WHO and USP/PQM and local manufacturers, prepared a five-year GMP Road Map (2013-18). It has assessed and mapped the GMP status of the local manufactures and categorized them into three GMP compliance levels (Level I with up to 50\% GMP compliance; Level II with 60-80\% GMP compliance; and, Level III with more than $80 \%$ GMP compliance). As per their levels, FMHCA and its partners are building the capacity of the local manufacturers for them to be GMP compliant by 2018 (FMHACA, 2013b).

A major scientific and technological project is the establishment of a Regional Bioequivalence Centre (RBEC) in Ethiopia. This presents yet another major opportunity for upgrading. To serve as substitutes, generic products should be bioequivalent or therapeutically equivalent to the originator/comparator products. Consequently, bioequivalence becomes even more crucial for generic products such as medicines for critical use (e.g. anti-retroviral, anti-tubercular), medicines with a narrow margin of safety (e.g. cardiovascular drugs), sustained or modified-release products and medicines with inherent solubility and permeability problems.

To obtain marketing authorization in different countries, manufacturers have to get their products approved and registered by the national drug registration authorities. Under normal circumstances, manufacturers are expected to present product pre-qualification for bioequivalence. However, local regulatory authorities could not enforce bioequivalence testing thus far, because the service fees charged by international contract research organizations are not affordable to the local manufacturers. Hence, the absence of a local bioequivalence testing facility in the subregion has been a big hurdle in the enforcement of the bioequivalence testing requirement of the generic medicines. 
To assist local manufacturers, the Regional Bioequivalence Centre Sh. Co. (RBEC) was recently established in Addis Ababa as a public-private partnership. GIZ provided the basic instruments and equipment for the bio-analytic laboratory and technical training to key staff. Addis Ababa University made available laboratory space and furnished offices. Two pharmaceutical manufacturing companies in Kenya (Universal Corporation Ltd and Skylight Chemicals Ltd), one local manufacturer in Ethiopia (Addis Pharmaceutical Factory PLC) and one generic manufacturer in Germany made modest financial contributions to cover the running costs of the Centre until it acquires the WHO prequalification and thereby begins to generate its own revenue. The Centre has a clinical partner, Armauer Hanssen Research Institute, where the clinical studies are being conducted.

Since RBEC is the first of its kind in the Sub-Saharan region (except for South Africa), the centre anticipates an overwhelming demand for BE studies. The Centre will also offer services related to assessment of quality of medicines. In the long run the RBEC would also play key role in clinical trials as well as in pharmaceutical research and development activities aiming at product development and drug discoveries.

The other important entity that has been recently (2013) established by Proclamation is the Food, Beverage and Pharmaceuticals Industry Development Institute, which has the objective of transforming the food, beverage and pharmaceutical industries through accelerated technological development and transfer. Currently, the Institute is preparing a 10-year strategic plan for the development of the pharmaceutical industry.

\section{Conclusion: future pathways and challenges}

Ethiopia is making substantial headway in all areas of socio-economic development. It is in the midst of a sustained growth surge that is becoming increasingly broad-based, building on major improvements in educational attainment, improved health outcomes and improved infrastructure capacity (power, transportation and telecommunications). The GTP sets ambitious targets for further improvements in these areas, together with significant reforms aiming to improve local manufacturing capacities (including pharmaceuticals) and trade logistics by rolling out various export-oriented economic programmes (Assefa et al., 2013).

Despite all these achievements, however, there are still outstanding issues to be addressed, such as the low production capacity and 
overwhelming dependence on importation of medicines; shortage of qualified management and technical personnel; and inadequate continuing professional development for practising professionals.

Asked about challenges and limitations faced by the local manufacturers, the plant technical manager of EAP reiterated the following: limited working capital of the factories; conflicts of interest with the suppliers of raw materials in India and China (as they are also producers of medicines, so they charge higher prices); paying VAT that is not reimbursed; shortage of foreign currency and hence longer lead time in foreign purchase resulting in price fluctuation and ultimately purchase reorders; small bulk orders with no economy of scale; low manufacturing capacity and hence high production cost; and limited capacity for troubleshooting and management.

Finally, based upon the assessment in this chapter, we suggest the following ways forward.

Strengthen local production: Although some progress has been made over the past few years, the development and local production of medicines is still marginal. Consequently, Ethiopia is relying heavily on imports for medicines and medical supplies. It is therefore crucial to build and strengthen national capacity to manufacture affordable, safe, efficacious, high-quality generic essential medicines which can significantly contribute to the simultaneous achievement of public health and industrial development objectives (MoST, 2012).

Competitive and efficient local pharmaceutical production should be promoted by strengthening local producers' capacity to meet WHO-GMP and WHO prequalification standards, promoting regional and international collaborations and facilitate technology transfer; fostering pooled procurement of raw materials and other inputs.

Establish raw material manufacturing plants: The fact that most raw materials have to be imported has made the local pharmaceutical manufacturers less competitive against imported generic products from Asia. Therefore, looking for alternative local sources of some of the excipients and APIs is one important strategy to improve the competitiveness of the local manufacturers (Gebre-Mariam and Schmidt, 1996, 1998; Gebre-Mariam et al., 1996) (see also Chapter 7). The government should foster such an endeavour.

Build human capital: The availability of adequate, appropriately trained and well-motivated personnel endowed with requisite knowledge, skills and attitude to provide effective and efficient services is of paramount importance for the development of the pharmaceutical industry. Some manufacturers report that local personnel are not adequately trained 
to carry out pharmaceutical production and business development. To rectify this, formal pharmaceutical training should be based on the needs of the industry. Strategies should be devised and implemented to update professionals who are in service.

Enhance research and development: R\&D on raw materials (APIs and excipients) should be fostered and long-term strategy for their local production should be planned and implemented. Research on product development to make local products competitive should be enhanced. More favourable conditions should be created for the introduction of appropriate technology and know-how to vitalize the industry. To develop the raw material base for the pharmaceutical industry and to enhance the growth of a viable domestic pharmaceutical industry and manufacturing capacities, the government should extend its support to the private sector engaged in raw materials production. Research collaboration between universities, research institutes and local manufacturers should be promoted.

\section{Notes}

Acknowledgements: The authors would like to extend their gratitude to Mr. Asmelash Gebre (Secretary, EPMSMA), Mrs. Zaf Gebre-Meskel (General Manager, SEAA), Mrs. Muna Ahmed (Technical Director, EAP), Mr. Shimelis Mamuye (General Manger APF), Mr. Mukemil Abdella (Country Director, Julphar), Mr. Shegaw Adreaw (Deputy General Manager, SEAA) and Mr. Girma Aweke (Procurement and Supply Head, EPHARM) for accepting interviews, for their valuable time and for providing us with invaluable information on the pharmaceutical sector and their respective companies.

1. http://effortinvestments.com/new/index.php/officer, accessed 10 December 2014.

2. http://www.rttnews.com/1687014/cadila-pharma-s-ethiopian-jv-receivescgmp-certificate.aspx, accessed 10 December 2014.

3. This facility used to belong to 'Bethelehem Pharmaceuticals PLC'. It was foreclosed during the crisis period, the Ethiopian Development Bank sold it out to Julphar, and the latter renovated the plant to meet GMP standards.

4. http://www.julphar.net.

5. http://www.pharmaceutical-technology.com/projects/julpharmanufacturing-facility-addis-ababa/.

6. http://allafrica.com/stories/201501190895.html Ethiopia: Julphar to Build Africa's Largest Injectable Medicine Plant.

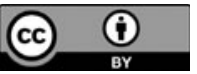

Except where otherwise noted, this work is licensed under a Creative Commons Attribution 4.0 Unported License. To view a copy of this license, visit https://creativecommons.org/version4 